\title{
Annexin A1 and the Resolution of Inflammation: Modulation of Neutrophil Recruitment, Apoptosis, and Clearance
}

\author{
Michelle Amantéa Sugimoto, ${ }^{1,2,3}$ Juliana Priscila Vago, \\ Mauro Martins Teixeira, ${ }^{3}$ and Lirlândia Pires Sousa ${ }^{1,2,3,4}$ \\ ${ }^{1}$ Programa de Pós-Graduação em Ciências Farmacêuticas, Faculdade de Farmácia, Universidade Federal de Minas Gerais, \\ 31270-901 Belo Horizonte, MG, Brazil \\ ${ }^{2}$ Departamento de Análises Clínicas e Toxicológicas, Faculdade de Farmácia, Universidade Federal de Minas Gerais, \\ 31270-901 Belo Horizonte, MG, Brazil \\ ${ }^{3}$ Laboratório de Imunofarmacologia, Departamento de Bioquímica e Imunologia, Instituto de Ciências Biológicas, \\ Universidade Federal de Minas Gerais, 31270-901 Belo Horizonte, MG, Brazil \\ ${ }^{4}$ Programa de Pós-Graduação em Biologia Celular, Departamento de Morfologia, Instituto de Ciências Biológicas, \\ Universidade Federal de Minas Gerais, 31270-901 Belo Horizonte, MG, Brazil
}

Correspondence should be addressed to Lirlândia Pires Sousa; lipsousa72@gmail.com

Received 29 August 2015; Accepted 1 December 2015

Academic Editor: Nicolas Demaurex

Copyright ( 2016 Michelle Amantéa Sugimoto et al. This is an open access article distributed under the Creative Commons Attribution License, which permits unrestricted use, distribution, and reproduction in any medium, provided the original work is properly cited.

\begin{abstract}
Neutrophils (also named polymorphonuclear leukocytes or PMN) are essential components of the immune system, rapidly recruited to sites of inflammation, providing the first line of defense against invading pathogens. Since neutrophils can also cause tissue damage, their fine-tuned regulation at the inflammatory site is required for proper resolution of inflammation. Annexin A1 (AnxA1), also known as lipocortin-1, is an endogenous glucocorticoid-regulated protein, which is able to counterregulate the inflammatory events restoring homeostasis. AnxAl and its mimetic peptides inhibit neutrophil tissue accumulation by reducing leukocyte infiltration and activating neutrophil apoptosis. AnxA1 also promotes monocyte recruitment and clearance of apoptotic leukocytes by macrophages. More recently, some evidence has suggested the ability of AnxAl to induce macrophage reprogramming toward a resolving phenotype, resulting in reduced production of proinflammatory cytokines and increased release of immunosuppressive and proresolving molecules. The combination of these mechanisms results in an effective resolution of inflammation, pointing to AnxAl as a promising tool for the development of new therapeutic strategies to treat inflammatory diseases.
\end{abstract}

\section{Introduction}

Inflammation is a crucial physiological response for the maintenance of tissue homeostasis, protecting the host against invading microorganisms, foreign substances, or host self-disturbers, such as the molecules derived from damaged cells [1]. After the host has been incited, important microcirculatory events occur in response to local release of proinflammatory mediators, such as histamine, prostaglandins, leukotrienes, cytokines, and chemokines, leading to higher vascular permeability and increased leukocyte recruitment [1]. Leukocytes, such as neutrophils and macrophages, play a key role in inflammatory response, by releasing further inflammatory mediators and acting as effector cells and phagocytes to remove the inflammatory agent/stimuli [2].

Despite the important roles of neutrophils for effective host defense, these cells can also cause tissue damage requiring appropriate regulation $[3,4]$. Continuous inflammatory stimuli can lead to aggressive and/or prolonged inflammatory responses, which may be detrimental to the host, leading to chronic inflammation [5]. The efficient removal of the inciting agent by phagocytes is the first signal for triggering proper resolution, through inhibition of proinflammatory mediators production and activation of their catabolism, 
resulting in the ceasing of further leukocyte recruitment [6]. After that, proresolving pathways are activated in order to restore tissue structure, function, and homeostasis $[7,8]$. In this context, anti-inflammatory and proresolving molecules such as specialized lipid mediators (lipoxin A4, resolvins, maresins, and protectins), peptides/proteins (melanocortins, galectins, and annexin $\mathrm{Al}$ ), and several other substances of different natures are released at the site of inflammation $[7,9,10]$. These endogenous mediators are known for their ability to decrease endothelial activation, reduce leukocyte infiltration, and activate neutrophil apoptosis, which ensures their secure removal by scavenger macrophages through a process called efferocytosis (phagocytosis of apoptotic cells) [4].

Annexin A1 (AnxA1) is an important glucocorticoid(GC-) regulated protein, which contributes to the resolution of inflammation through various ways (Figure 1). AnxA1 limits neutrophil recruitment and production of proinflammatory mediators. Moreover, AnxAl acts by inducing neutrophil apoptosis, modulating monocyte recruitment, and enhancing the clearance of apoptotic cells by macrophages. Emerging evidence suggests that AnxAl also induces macrophage reprogramming toward a resolving phenotype, another key event to restore tissue homeostasis. In this review, we summarize several physiological and potential therapeutic actions of AnxA1 on inflammation resolution. In particular, this review highlights recent advances on the actions of this endogenous mediator and its potential clinical utility.

\section{Annexin A1: General Aspects}

Endogenous mediators of inflammation, such as AnxAl, are potential therapeutic tools to control inflammatory diseases. Although whether clinical use of proresolving strategies will be useful for treating inflammatory maladies or will show significant undesirable effects remains to be elucidated, it is believed these will be effective and have fewer side effects due to their ability to mimic or induce natural pathways of the resolution phase of inflammation $[8,12]$.

Annexin superfamily is composed of 13 members, grouped in view of their unique $\mathrm{Ca}^{2+}$-binding-site architecture, which enables them to peripherally attach to negatively charged membrane surfaces [13-15]. AnxA1, also known as annexin I or lipocortin I, was originally identified as a GC-induced protein active on phospholipase- (PL-) A2 inhibition and prevention of eicosanoid synthesis [16-18]. It was subsequently recognized as an endogenous modulator of the inflammatory response, through several studies, mainly those led by Dr. Flower and Dr. Perretti [19, 20]. This $37 \mathrm{kDa}$ protein consists in a homologous core region of 310 amino acid residues, representing almost $90 \%$ of the structure, attached to a unique $\mathrm{N}$-terminal region [15]. In addition to mediating membrane binding, $\mathrm{Ca}^{2+}$ ions can also induce a conformational change that leads to the exposure of the bioactive $\mathrm{N}$-terminal domain $[15,21,22]$. In fact, studies on the anti-inflammatory activity of AnxAl revealed not only that the different functions of the protein lie within the unique N-terminus, but also that synthetic peptides from the N-terminal domain may mimic the pharmacological property of the whole protein, specifically binding to formyl peptide receptors (FPRs) [12].

In inflammatory conditions intact AnxAl $(37 \mathrm{kDa})$ can be cleaved by proteinase- 3 and neutrophil elastase generating the $33 \mathrm{kDa}$ cleaved isoform, which is believed to be inactive, and peptides derived from the AnxA1 N-terminus [23-25]. The main cleavage sites on AnxAl are located at $\mathrm{A}^{11}, \mathrm{~V}^{22}$, and $\mathrm{V}^{36}$, as identified by cleavage assays coupled to mass spectrometric analyses [25]. Investigation of the $\mathrm{AnxAl}_{2-50}$ peptide revealed a novel cleavage site at position 25, probably unmasked due to the simpler conformation of the peptide, compared with the full-length AnxA1 [26]. In fact, the substitution of the mentioned cleavage sites allowed the generation of metabolically stable forms of AnxAl and its peptide, respectively, named SuperAnxAl (SAnxA1) [27] and cleavage-resistant $A n x A 1_{2-50}$ (CR-AnxA1 ${ }_{2-50}$ ) [26]. The proinflammatory nature of AnxAl cleavage products is supported by reports of increased levels of the $33 \mathrm{kDa}$ fragment in human and animal inflammatory samples, including bronchoalveolar lavage fluids [28-30] and exudates [11, 25, 31, 32]. For instance, using a model of acute pleurisy, our research group has shown increased levels of the $33 \mathrm{kDa}$ breakdown product of AnxAl during the time points of high neutrophil infiltration into the pleural cavity followed by regain of the intact form during the resolving phase of the pleurisy [11]. However, what the biological functions of this and other AnxAl-generated peptides are is still unclear, and this matter deserves further investigation.

Evidence for physiological function of AnxA1 in modulating inflammation emerged from studies involving AnxA1null mice and AnxA1 neutralization strategies. AnxA1-null mice are viable and have a normal phenotype until they are challenged with inflammatory stimuli when they show stronger and more prolonged inflammatory reaction when compared to the wild-type (WT) [33-40]. Resistance to glucocorticoid treatment and aberrant inflammation in AnxA1deficient mice provided initial evidence for the physiological relevance of the protein [33]. In the absence of AnxA1, the inflammatory response is exacerbated as demonstrated by increased neutrophil extravasation following zymosaninduced peritonitis [35] and endotoxin-induced uveitis [37]. In addition, animals lacking this protein exhibited exacerbated arthritis severity [34] and allergic response in ovalbumin-induced conjunctivitis [39]. AnxA1 KO mice also showed increased atherosclerotic lesion size with an overall increase in lesional macrophages and neutrophils [40]. Moreover, our research group has shown the prevention of spontaneous and dexamethasone-driven resolution of inflammation by using an AnxAl neutralizing strategy [11]. Aside from the physiological role of the endogenous protein, pharmacological treatment with both human recombinant AnxAl and its $\mathrm{N}$-terminal peptides exerts anti-inflammatory and proresolving effects in a variety of experimental models, highlighting their therapeutic potential for inflammation resolution [11, 26, 27, 41] and wound repair [42].

AnxAl exerts many of its anti-inflammatory and proresolving actions through the formyl peptide receptor type 


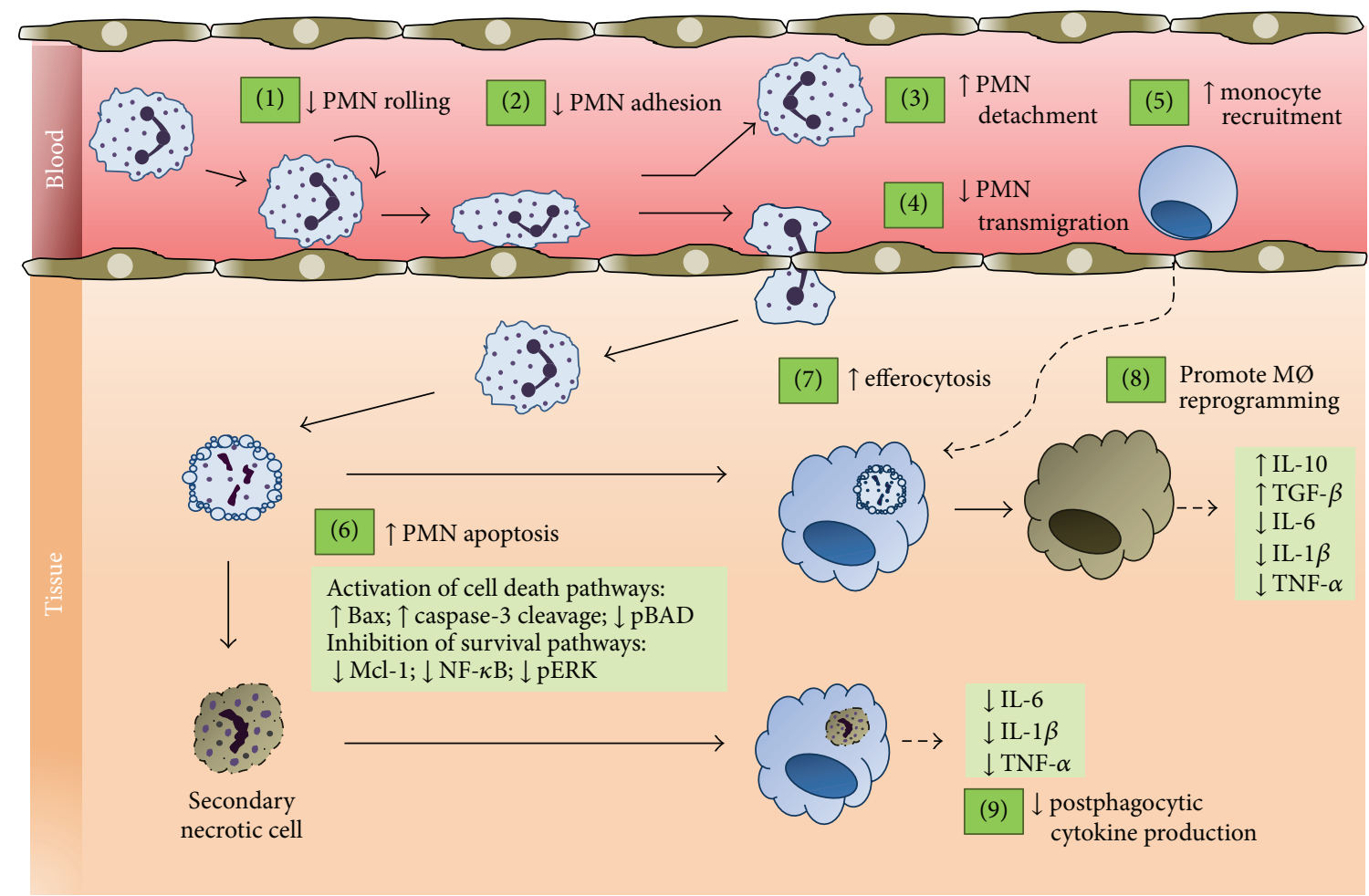

FIGURE 1: Cellular events associated with the anti-inflammatory and proresolving effects of annexin A1 (AnxAl) and its mimetic Nterminal peptides. AnxA1 modulates a wide range of cellular and molecular steps of the inflammatory response and is deeply involved in the endogenous mechanisms that are activated to bring about proper resolution. Pharmacological administration of AnxAl results in decreased neutrophil rolling (1) and adhesion (2) to endothelium, increased detachment of adherent cells (3), and inhibition of neutrophil transmigration (4). In addition, AnxA1 is able to induce apoptosis, overriding the prosurvival signals that cause prolonged lifespan of neutrophils at the inflammatory site (6). Endogenous and exogenous AnxAl also promote monocyte recruitment (5) and clearance of apoptotic neutrophils by macrophages (7). Phagocytosis of apoptotic neutrophils by macrophages is coupled with release of anti-inflammatory signals, including transforming growth factor- $\beta$, and lower levels of proinflammatory cytokines (8). Besides, AnxA1 is related to macrophage reprogramming toward a proresolving phenotype (8). Initial in vitro studies using AnxA1 knock-down leucocytes demonstrate that AnxA1 prevents proinflammatory cytokine production after phagocytosis of secondary necrotic cells. This effect provides an important fail-safe mechanism counteracting inflammatory responses when the timely clearance of apoptotic cells has failed (9).

2/lipoxin A4 receptor (FPR2/ALX). This receptor, along with FPR1 and FPR3, composes a family of seven-transmembrane domain $\mathrm{G}$ protein-coupled receptors which share significant sequence homology [43]. FPR2/ALX receptor is shared by a variety of other peptide/protein and lipid ligands, mediating diverse biological functions of relevance for host defence and inflammation. Interestingly, FPR2/ALX agonists are associated with both proinflammatory (e.g., serum amyloid $A$ and cathelicidin) and proresolving (e.g., AnxAl and $\mathrm{LXA}_{4}$ ) signalling pathways $[43,44]$. However, how FPR2/ALX can promote both inflammatory response and limit its duration and intensity still remains to be fully elucidated. It is noteworthy that distinct FPR2/ALX domains are required for signalling by different agonists [45]. Using FPR2/ALX transfected cells and chimeric FPR1 and FPR2 clones, Bena and col. (2012) identified that while AnxAl-mediated signalling involves the $\mathrm{N}$-terminal region and extracellular loop II of FPR2/ALX, SAA interacts with the extracellular loops I and II of the same receptor [45]. Otherwise, $\mathrm{LXA}_{4}$ has been shown to activate FPR2/ALX by interacting with extracellular loop III and the associated transmembrane domain [46].
The versatility of FPR2/ALX receptors also seems to rely on the activation of receptor dimmers in a biased fashion. AnxA1 was found to activate FPR2/ALX homodimerization but not the proinflammatory SAA [47]. In contrast to the full-length AnxA1, the short AnxA1 derived peptide Ac226 is able to activate all members of the human FPR family [48] and induce FPR2/ALX-FPR1 heterodimerization [47]. These observations suggest that short AnxA1 mimetic peptides might fulfill other functions at variance to those reported for the parental protein [49]. However, a good degree of selectivity was retained by longer AnxAl derived anti-inflammatory sequences such as $\mathrm{AnxA1}_{2-50}$ [26].

Interestingly, the promiscuity of FPR2/ALX seems to be linked to a network of resolution mediators as discussed by Brancaleone and col. (2011) [50]. In fact, the authors provide strong evidence that the engagement of FPR2/ALX by selective agonists (such as $\mathrm{LXA}_{4}$ and antiflammin 2) would induce AnxA1 phosphorylation and mobilization in human PMN [50]. In a similar vein, the proresolving mediator Resolvin E1 (RvE1) stimulates endogenous $\mathrm{LXA}_{4}$ production $[51,52]$. Moreover, it has been shown that proresolving 
mediators such as resolvins and $\mathrm{LXA}_{4}$ induce further antiinflammatory molecules in vivo, such as interleukin- (IL-) 10 [41]. Taken together, these data suggest that a proresolving cascade may be operating during resolution with FPR2/ALX playing a central role in this process.

\section{Anti-Inflammatory and Proresolving Actions of AnxA1}

3.1. AnxA1 Regulates Neutrophil Recruitment to the Inflammatory Site. During inflammation neutrophils are rapidly recruited to the infected or injured tissue. However, due to the potential tissue-damaging effects of PMN, their finetuned regulation at the inflammatory site is required [53]. Indeed, exacerbated or overshooting inflammatory response with high neutrophil influx may account for chronic inflammatory diseases [5]. Thus, restricting leukocyte infiltration to the tissue is an essential process for spontaneous or pharmacological-induced resolution of inflammation $[4,8]$.

Neutrophil trafficking to the site of inflammation requires adhesion and transmigration through blood vessels, which is orchestrated by molecules on leukocytes (e.g., $\beta 1, \beta 2$ integrins, and L-selectin) and on endothelial cells (e.g., vascular cell adhesion molecule-1, intercellular adhesion molecule-1, and E-selectin). The leukocyte adhesion cascade is a tightly regulated process, subjected to both positive and negative regulators [71]. For example, anti-inflammatory and proresolving mediators, such as AnxA1, are well documented to counterregulate excessive neutrophil accumulation (an anti-inflammatory action). Human PMN interaction with endothelial cells during the early stage of inflammation promotes modulation of AnxA1 in several ways, such as induction of gene expression [35] and mobilization and cell surface externalization of intracellular AnxA1 $[72,73]$. In turn, the externalized protein acts as a brake for PMN adhesion to the microvascular wall, preventing overexuberant cell transmigration to the inflammatory site $[4,27,72,74]$. Dalli and col. (2008) [75] reinforced the anti-inflammatory properties of PMN-derived microparticles containing functionally active AnxA1. Released upon adhesion to endothelial cells, these microparticles inhibit neutrophil/endothelium interaction under flow, in vitro, and PMN recruitment to an air pouch inflamed with IL-1 $\beta$, in vivo [75]. Moreover, microparticles derived from WT but not from AnxA1-deficient neutrophils were able to inhibit IL-1 $\beta$-induced leukocyte trafficking [75].

Several studies using exogenously administrated AnxA1 have provided further evidence for the modulating role of AnxA1 on neutrophil trafficking. In vivo observations produced through intravital microscopy techniques indicated that AnxA1 and Ac2-26 administration to mice during zymosan-induced peritonitis produced detachment of adherent neutrophils from the vascular wall with consequent inhibition of neutrophil extravasation across mouse mesenteric postcapillary venules (Table 1) [56]. Supporting these first findings, in vitro studies showed that recombinant AnxA1 and its mimetic peptides display inhibitory effects on neutrophil rolling [26, 27, 54, 55] adhesion to endothelial monolayer $[26,27,40,48,54,55]$ and transmigration [48].
Shedding of L-selectin appears to be one of the molecular mechanisms that mediate the effects of AnxA1 and its Nterminal peptides on neutrophil recruitment. Walther and col. (2000) [48] have described the ability of the AnxA1 peptide Ac9-25 to cause transient calcium fluxes and Lselectin shedding in human neutrophils. After that, the same mechanism was linked to the inhibitory effects of Ac2-26 on PMN capture and rolling in a flow chamber assay [54]. Similarly, promotion of L-selectin shedding was demonstrated for human recombinant AnxA1 [57, 58], an effect mediated by cell surface metalloprotease ("sheddase") [58]. Recently, Drechsler and col. (2015) [40] brought further insights into the mechanisms behind the antimigratory effects of Ac226. According to the authors, the peptide dose dependently reduces the affinity of activated neutrophils for vascular cell adhesion molecule-1 (VCAM-1) and intercellular adhesion molecule-1 (ICAM-1), a response abrogated in cells harvested from FPR2 knockout mice. They demonstrated that Ac2-26 inhibits the adhesiveness of $\beta 1$ and $\beta 2$ integrins by downmodulating their affinity and valency, but without changing their cell surface expression. It was also demonstrated that Ac2-26 interferes with the chemokine-driven activation of Rapl, an essential step in integrin activation $[76,77]$.

Pederzoli-Ribeil and col. (2010) [27] combined in vitro and in vivo experimental strategies to show that AnxAl and its mutant cleavage-resistant form, SAnxA1, are able to augment rolling velocity and reduce adhesion of PMN to endothelial cells through FPR2 receptors. Furthermore, Dalli and col. (2013) [26] demonstrated the anti-inflammatory actions of the longer acetylated AnxAl peptide $\mathrm{AnxA1}_{2-50}$ and its cleavage-resistant form, CR-AnxA1 $1_{2-50}$. Both displayed antimigratory effects in vivo, reducing leukocyte adhesion to inflamed cremaster venule, neutrophil migration into dermal air pouches in response to IL- $1 \beta$, and neutrophil migration into peritoneum in response to zymosan.

In vivo anti-inflammatory and antimigratory properties of the short AnxA1 peptide Ac2-26 have also been extensively demonstrated, as exemplified by its ability to inhibit carrageenan-induced PMN adhesion to the vasculature and extravasation into the peritoneal fluid [74]. The peptide was also able to prevent neutrophil recruitment in myotoxininduced peritonitis [78] and during lung inflammation induced by intestinal ischemia/reperfusion [79]. Moreover, Ac2-26 showed potential benefits in an ocular model by inhibiting neutrophil influx, protein leak, chemical mediator release, and COX-2 expression during endotoxin-induced uveitis [37]. The Ac2-26 peptide also demonstrated antimigratory effects in a model of ovalbumin-induced allergic conjunctivitis, significantly reducing the clinical signs of conjunctivitis through the inhibition of leukocyte influx and cytokines and chemokines release, effects correlated with inhibition of the ERK pathway [39]. Interestingly, increased levels of ERK phosphorylation were associated with exacerbated allergic response observed in AnxA1-deficient mice in comparison to WT animals [39]. Reinforcing the involvement of AnxAl pathway in neutrophil recruitment, AnxA1-null mice demonstrated a higher extent of neutrophil extravasation in animal models of peritonitis [35, 74], allergic conjunctivitis [39], and uveitis [37]. 
TABLE 1: In vitro and in vivo evidence for anti-inflammatory and proresolving properties of annexin A1 and its fragments.

\begin{tabular}{|c|c|c|c|}
\hline Agent & Experimental model & Outcome/effect on resolution & References \\
\hline \multicolumn{4}{|c|}{ Inhibition of neutrophil recruitment } \\
\hline \multirow{5}{*}{ AnxA1 } & Neutrophil/endothelial interaction (in vitro) & $\begin{array}{l}\downarrow \text { PMN capture, rolling, and adhesion } \\
\downarrow \text { PMN transmigration }\end{array}$ & {$[27,48,54,55]$} \\
\hline & Neutrophil/endothelial interaction (in vivo) & $\begin{array}{l}\downarrow \text { PMN rolling, adhesion, and emigration } \\
\uparrow \text { Detachment of adherent PMN }\end{array}$ & {$[27,56]$} \\
\hline & Human PMN & $\uparrow \mathrm{L}$-selectin shedding & {$[57,58]$} \\
\hline & IL-1 $\beta$ inflamed air pouch & $\downarrow$ PMN migration & {$[26,59]$} \\
\hline & Carrageenan-induced paw edema & $\begin{array}{l}\downarrow \text { edema } \\
\downarrow \text { leukocyte infiltration }\end{array}$ & {$[27]$} \\
\hline \multirow{4}{*}{ SAnxA1 } & Neutrophil/endothelial interaction (in vitro) & $\downarrow$ PMN capture, rolling, and adhesion & {$[27]$} \\
\hline & Neutrophil/endothelial interaction (in vivo) & $\downarrow$ PMN rolling and adhesion & {$[27]$} \\
\hline & fMLP induced skin edema & $\downarrow$ MPO activity & {$[27]$} \\
\hline & Carrageenan-induced paw edema & $\begin{array}{l}\downarrow \text { edema } \\
\downarrow \text { leukocyte infiltration }\end{array}$ & {$[27]$} \\
\hline \multirow{3}{*}{$\operatorname{AnxA1}_{2-50}$} & Neutrophil/endothelial interaction (in vitro) & $\downarrow \mathrm{PMN}$ rolling and adhesion & {$[26]$} \\
\hline & Neutrophil/endothelial interaction (in vivo) & $\downarrow \mathrm{PMN}$ adhesion & {$[26]$} \\
\hline & IL- $1 \beta$ inflamed air pouch & $\downarrow$ PMN recruitment & {$[26]$} \\
\hline \multirow{3}{*}{ Ac2-26 } & Neutrophil/endothelial interaction (in vitro) & $\begin{array}{l}\downarrow \text { PMN capture, rolling, and adhesion } \\
\uparrow \text { L-selectin shedding }\end{array}$ & {$[40,54]$} \\
\hline & Human PMN activated with CCL5 & $\downarrow \beta$ integrin activation & {$[40]$} \\
\hline & Neutrophil/endothelial interaction (in vivo) & $\begin{array}{l}\downarrow \text { PMN adhesion and emigration } \\
\uparrow \text { detachment of adherent PMN }\end{array}$ & {$[56]$} \\
\hline Acl-26 & Neutrophil/endothelial interaction (in vitro) & $\downarrow$ PMN transmigration & {$[48]$} \\
\hline Ac9-25 & Neutrophil/endothelial interaction (in vitro) & $\begin{array}{l}\downarrow \text { PMN adhesion and transmigration } \\
\uparrow \text { L-selectin shedding }\end{array}$ & {$[48]$} \\
\hline $\mathrm{AF}-2$ & Neutrophil/endothelial interaction (in vitro) & $\begin{array}{l}\downarrow \mathrm{PMN} \text { adhesion } \\
\downarrow \beta 2 \text { integrin expression }\end{array}$ & {$[60,61]$} \\
\hline \multicolumn{4}{|c|}{ Induction of neutrophil apoptosis } \\
\hline AnxA1 & Human PMN & $\uparrow$ apoptosis $(\downarrow$ pBAD $)$ & {$[57]$} \\
\hline $\mathrm{AnxA1}_{2-50}$ & Human neutrophils stimulated with SAA & $\uparrow$ apoptosis & {$[26]$} \\
\hline \multirow{3}{*}{ Ac2-26 } & Human neutrophils stimulated with SAA & $\begin{array}{l}\uparrow \text { apoptosis } \\
\text { ( } \uparrow \text { caspase- } 3 \text { cleavage; JNK dependent) }\end{array}$ & {$[47]$} \\
\hline & Acute pleurisy & $\begin{array}{l}\uparrow \text { apoptosis } \\
(\uparrow \mathrm{Bax} ; \uparrow \text { caspase- } 3 \text { cleavage; } \\
\downarrow \text { Mcl- } 1 ; \downarrow \text { NF- } \kappa \mathrm{B} ; \downarrow \text { pERK) }\end{array}$ & {$[11]$} \\
\hline & Skin allograft model & $\begin{array}{l}\uparrow \text { skin allograft survival } \\
\uparrow \text { apoptosis } \\
\downarrow \text { neutrophil transmigration }\end{array}$ & {$[62]$} \\
\hline \multicolumn{4}{|c|}{ Enhancement of monocyte recruitment and efferocytosis } \\
\hline Ac2-7 & Transmigration assay (in vitro) & Stimulating human monocyte chemotaxis & {$[63]$} \\
\hline \multirow{3}{*}{ AnxA1 } & Chemotaxis assays & Human monocyte chemoattractant & {$[64]$} \\
\hline & Administration to mouse peritoneum & $\uparrow$ monocyte recruitment & {$[64]$} \\
\hline & Phagocytosis of apoptotic leukocytes & $\begin{array}{l}\uparrow \text { efferocytosis } \\
\uparrow \text { binding of apoptotic cells to MØ }\end{array}$ & {$[65,66]$} \\
\hline Ac2-26 & Phagocytosis of apoptotic neutrophils & $\begin{array}{l}\uparrow \text { phagocytosis } \\
\text { Inducing actin reorganization } \\
\uparrow \text { TGF- } \beta \text { release } \\
\downarrow \text { IL-8 release }\end{array}$ & {$[67]$} \\
\hline $\mathrm{AnxA1}_{2-50}$ & Zymosan-induced peritonitis & $\uparrow$ efferocytosis & [26] \\
\hline
\end{tabular}


TABLE 1: Continued.

\begin{tabular}{|c|c|c|c|}
\hline Agent & Experimental model & Outcome/effect on resolution & References \\
\hline \multicolumn{4}{|c|}{ Macrophage reprogramming } \\
\hline \multirow{6}{*}{ AnxA1 } & Human $M \varnothing$ cell line & Induced M2-like polarization & {$[44]$} \\
\hline & Human monocytes & $\uparrow \mathrm{IL}-10$ & {$[47]$} \\
\hline & LPS stimulated THP-1 MØ & $\downarrow$ IL-6, TNF, and IL-1 $\beta$ & {$[66]$} \\
\hline & MØ from NASH livers & $\begin{array}{l}\downarrow \text { M1 polarization ( } \downarrow \text { iNOS, IL-12p40) } \\
\uparrow \text { IL-10 }\end{array}$ & {$[68]$} \\
\hline & Intraperitoneal injection & $\uparrow \mathrm{IL}-10$ & {$[47]$} \\
\hline & Phagocytosis of apoptotic neurons by microglial cells & $\begin{array}{l}\downarrow \text { phagocytosis of healthy cells } \\
\downarrow \text { NO production }\end{array}$ & [69] \\
\hline Ac2-26 & Endotoxin-challenged monocytes & $\begin{array}{l}\downarrow \text { IL- } 6 \text { signalling } \\
\downarrow \text { TNF- } \alpha \text { release }\end{array}$ & {$[70]$} \\
\hline
\end{tabular}

AnxA1: annexin A1; fMLP: N-Formyl-Met-Leu-Phe; IL: interleukin; MPO: Myeloperoxidase; M $\varnothing$, macrophage; NASH; nonalcoholic steatohepatitis; PMN: polymorphonuclear; NO: nitric oxide; SAA: serum amyloid A; SAnxA1: SuperAnxA1 (proteinase- 3 resistant); TGF- $\beta$ : transforming growth factor- $\beta$; TNF- $\alpha$ : tumor necrosis factor alpha.

AnxA1 may also be tightly coupled to the anti-inflammatory properties of other FPR2/ALX agonists such as $\mathrm{LXA}_{4}$ and antiflammin 2 (AF-2) [50]. The nonapeptide AF-2, which corresponds to region 246-254 of AnxA1 [80], is known to interfere with PMN activation, chemotaxis, and adhesion to endothelial cells $[60,61]$, via FPR2/ALX receptor [81]. Also, $\mathrm{LXA}_{4}$ is a potent regulator of PMN trafficking in experimental inflammation $[9,82]$. Interestingly, recent data indicated a crucial role for endogenous AnxA1 in the detachment phenomenon promoted by both compounds [50]. For instance, $\mathrm{LXA}_{4}$ and AF-2 lost their antimigratory effects in AnxA1 KO mice suggesting AnxA1 as a downstream mediator of other proresolving and anti-inflammatory molecules [50].

3.2. AnxA1 Induces Neutrophil Apoptosis. Neutrophils are produced in the bone marrow from myeloid stem cells, which in turn proliferate, differentiate into mature neutrophils, and are delivered into circulation [83]. Although the circulatory half-life of neutrophils is now thought to be longer than previously estimated (days instead of hours) [84], at inflammatory sites the constitutive apoptotic pathway is delayed by the action of local inflammatory mediators, resulting in increased neutrophil half-life [85], an effect that can be opposed by proresolving mediators including AnxA1 and lipoxins [86].

In addition to affecting the migration of leukocytes through FPR activation, strong evidence of the involvement of AnxA1 on neutrophil apoptosis has emerged. Proapoptotic effect of AnxA1 on neutrophils was first described in vitro associated with transient calcium fluxes and dephosphorylation of $\mathrm{BAD}$, an intracellular protein whose proapoptotic function is lost upon phosphorylation [57]. Our group [11] demonstrated the in vivo proapoptotic functions of endogenous AnxA1 during self-resolving inflammation. In an acute pleurisy model, blockage of the AnxA1 pathway by using a specific anti-AnxA1 antiserum prevented dexamethasone(dexa-) induced resolution of neutrophilic inflammation, abolishing morphological and biochemical apoptotic events in the pleural cavity. AnxAl neutralization also hampered dexa-induced decrease of ERK1/2 and I $\kappa \mathrm{B}-\alpha$ phosphorylation and Bax accumulation. In addition, anti-AnxAl treatment prevented spontaneous resolution of neutrophilic inflammation, suggesting an important role of endogenously produced AnxA1 in the proresolutive program [11]. Furthermore, pharmacological administration of Ac2-26 peptide promoted active resolution and augmented the extent of neutrophil apoptosis. These effects were prevented by the pan-caspase inhibitor zVAD-fmk and linked to activation of the cell death pathways Bax and caspase- 3 and inhibition of the survival-controlling pathways Mcl-1, ERK1/2, and NF- $\kappa \mathrm{B}$ [11] (Figure 2).

In a skin allograft model, pharmacological treatment with Ac2-26 increased transplantation survival related to inhibition of neutrophil transmigration and induction of apoptosis, thereby reducing the tissue damage compared with control animals [62]. In vitro, Ac2-26 counteracted the survival signal in SAA-treated neutrophils, an effect associated with caspase-3 cleavage and prevented by the JNK inhibitor [47]. Dalli and col. (2013) also demonstrated that $\mathrm{AnxAl}_{2-50}$ and CR-AnxA1 $1_{2-50}$ peptides can override the antiapoptotic effect of SAA in human neutrophils in vitro [26]. This proapoptotic effect may have contributed to the in vivo anti-inflammatory and proresolving actions of the peptides characterized by reduced granulocyte counts and enhanced efferocytosis in peptide-treated mice during peritonitis [26].

AnxA1 has also been described as a mediator of druginduced apoptosis, supporting its involvement in the induction of cell death. The proapoptotic effect described for the histone deacetylase inhibitor (HDCAI) FK228, in leukemia cells, was linked to the induction of AnxA1 expression, externalization, and cleavage. Neutralization with anti-AnxA1 antibody or gene silencing with AnxAl siRNA inhibited FK228-induced apoptosis, suggesting the involvement of AnxA1 in apoptotic cell death in response to HDCAI [87]. Recently, the in vitro ability of HDACIs to promote apoptosis was also demonstrated in bone-marrow neutrophils from WT but not from AnxA1 knockout mice [88]. In vivo, HDACIs significantly reduced neutrophil numbers and 


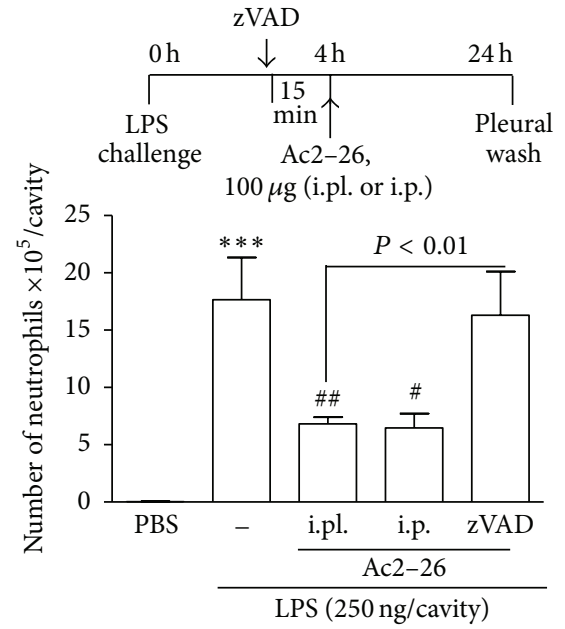

(a)
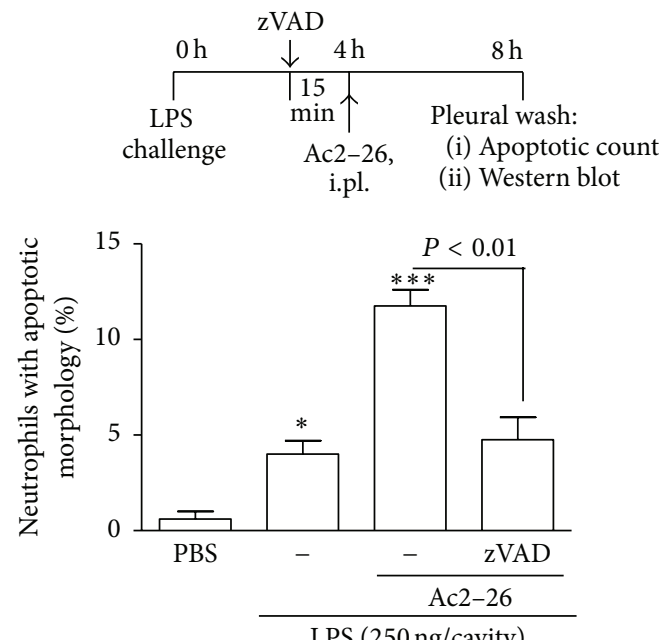

(c)

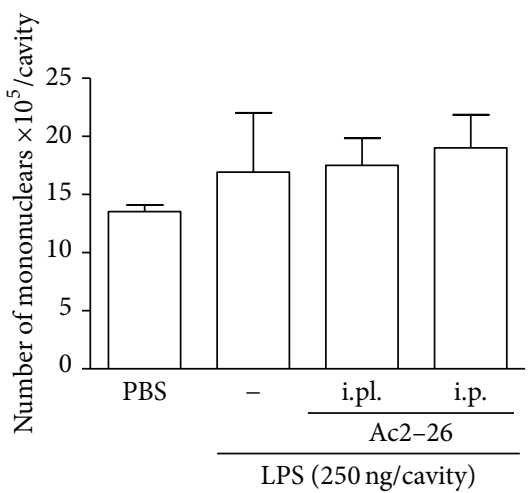

(b)

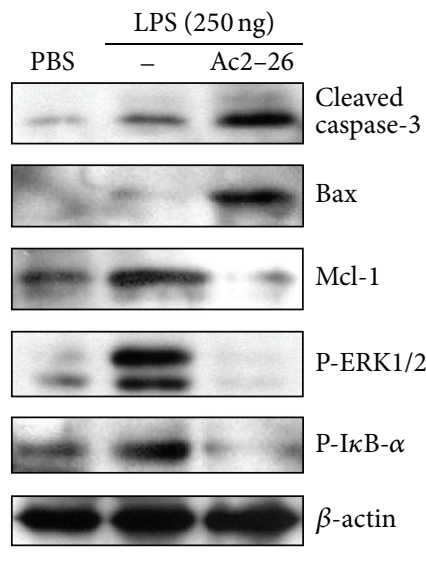

(d)
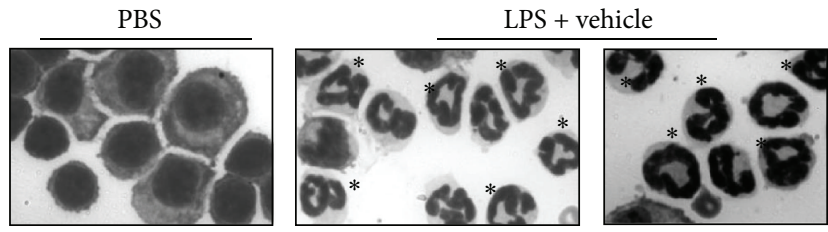

LPS + Ac2-26
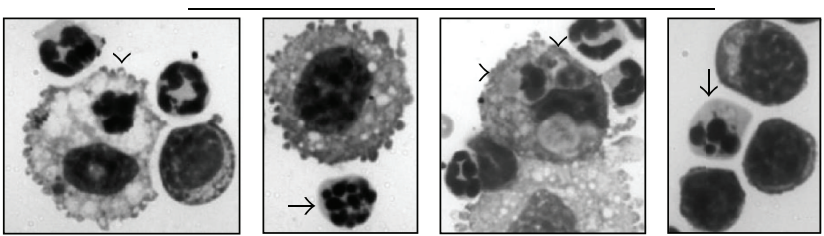

(e)

FIGURE 2: Effect of exogenous administration of AnxA1 derived peptide Ac2-26 on LPS-induced pleurisy. Mice were injected with LPS $(250 \mathrm{ng} /$ cavity, i.pl.) and $4 \mathrm{~h}$ later received an injection of Ac2-26 $(100 \mu \mathrm{g} / \mathrm{mouse}$, i.pl. or i.p.). The treatment with the pan-caspase inhibitor zVAD-fmk (1 mg/kg, i.p.) was performed $15 \mathrm{~min}$ before the injection of peptide. The numbers of neutrophils (a) and mononuclear cells (b) were evaluated $20 \mathrm{~h}$ after drug treatment. Cells with distinctive apoptotic morphology (c and e) and Western blot for detection of cleaved caspase-3, Bax, Mcl-1, P-ERK, and P-I $\kappa$ B- $\alpha$ (d) were evaluated $4 \mathrm{~h}$ after the peptide treatment. ${ }^{*} P<0.05$ or ${ }^{* * *} P<0.001$ when compared with PBS-injected mice and ${ }^{\#} P<0.05$ or ${ }^{\# \# P}<0.01$ when compared with vehicle-treated, LPS-injected mice. (e) Representative figures of nonapoptotic (asterisk) and apoptotic (arrows) neutrophils and apoptotic cells inside macrophages (arrowheads). PBS and vehicle (upper panels) and Ac2-26-treated (lower panels) animals are shown. Original data from Vago et al., 2012 [11]. 
induced neutrophil apoptosis in a zymosan-induced peritonitis model. Once again, the lack of AnxA1 hampered this in vivo proapoptotic effect [88].

It is important to keep in mind that the proapoptotic effect of AnxAl can be underestimated in dynamic in vivo models of inflammation. Regarding other anti-inflammatory drugs, it is documented in a number of diverse experimental and clinical settings that small changes in apoptosis rates can promote dramatic changes in total neutrophil numbers over time. This observation is most likely due to rapid recognition and phagocytosis of apoptotic cells [89-91].

\subsection{AnxA1 Induces Monocyte Recruitment and Increases} Efferocytosis. Macrophage phagocytic clearance of apoptotic neutrophils plays an important role in the resolution of inflammation since this process prevents excessive neutrophil activation and the exposure of tissues to noxious neutrophil intracellular contents [92, 93]. For this reason, appropriate (nonphlogistic) monocyte recruitment from the bloodstream to inflammatory sites is a critical step in acute inflammation, enabling the clearance of apoptotic neutrophils and orderly progression towards resolution.

It has long been established that extravasation of PMN to the site of inflammation contributes to the launch of monocyte recruitment, with PMN granule proteins being important monocyte attractors [94]. Recent research from Perretti's group [64] indicates apoptotic neutrophils as the principal reservoir of AnxA1, which acts as important recruiting agent for monocytes to orchestrate the second resolving phase of acute inflammation. Associating in vitro and in vivo experiments, Professor Mauro Perretti's group filled an important gap in our knowledge by demonstrating the central role of the AnxA1-ALX/FPR2 pathway in modulating monocyte recruitment [64]. The authors demonstrated that intraperitoneal administration of AnxA1 induced monocyte migration, an effect absent in FPR2 null mice. Supporting these findings, both AnxA1 and FPR2/ALX null mice challenged with intraperitoneal zymosan exhibited diminished recruitment of monocytes as compared to WT mice, despite the higher levels of chemoattractants [64].

After initial steps of apoptosis, neutrophils lose their functional properties, such as the ability to move by chemotaxis, generate a respiratory burst, or degranulate [95]. Furthermore, they exhibit alterations on their intracellular pathways and cell surface molecules while some externalized molecules, such as phosphatidylserines (PS), facilitate the recognition and removal of apoptotic neutrophils by macrophages $[92,96]$.

Recent studies have reported that AnxA1 from apoptotic cells is involved in their phagocytic clearance. The first observation that AnxAl participates in the engulfment of apoptotic cells was described by Arur and col. (2003) [97]. By using a differential proteomics technology, they showed that AnxA1 is exported to the outer plasma membrane of apoptotic lymphocytes, colocalizes with PS, and is required for efficient clearance of apoptotic cells, suggesting a role for AnxA1 as bridging PS molecules on apoptotic cells to phagocytes [97]. Scannell and col. (2007) [65] subsequently demonstrated that apoptotic neutrophils release AnxA1, which acts on macrophages, promoting the removal of effete cells [65]. Noteworthily, not only the intact form of AnxA1 released by apoptotic cells but also the cleavage fragments, under $10 \mathrm{kDa}$, were effective in stimulating efferocytosis [65].

Studies have also documented macrophages as a source of endogenous AnxA1, which in turn facilitates phagocytic uptake of apoptotic cells. Maderna and col. (2005) showed that human macrophages release AnxA1 upon treatment with GC and that this protein acts in autocrine or paracrine manners to increase the engulfment of apoptotic neutrophils [67]. Additional experiments with AnxA1-null mice provided further evidence for a functional role of AnxA1 in efferocytosis, as macrophages derived from their bone marrow were defective in clearance of apoptotic cells [67]. In fact, the authors demonstrated, in vitro, the ability of the AnxA1 mimetic peptide Ac2-26 to promote phagocytosis of apoptotic PMN by human macrophages, an effect associated with actin rearrangement in the phagocytic cells and abrogated in the presence of FPR antagonist [67]. Subsequently, it was clearly demonstrated the nonredundant function of FPR2/ALX receptor in Ac2-26 induced efferocytosis since the peptide failed to exert its proefferocytic action on FPR2/ ALX deficient macrophages [98]. Furthermore, Yona and coworkers (2006) associated in vitro and in vivo strategies that indicated reduced phagocytosis of zymosan particles by AnxA1 knockout macrophages [99].

It has been proposed that AnxA1 released by macrophages can opsonize apoptotic cells, probably by interacting with surface-exposed PS, enhancing their uptake by phagocytes [66]. Interestingly, McArthur's group demonstrated that the binding of microglial-derived AnxA1 to PS on the surface of apoptotic neuronal cells is critically required for phagocytosis [69]. Moreover, Dalli and colleagues (2012) reported that AnxA1 expressed by resident macrophages is a critical determinant for the clearance of senescent neutrophils in the bone marrow [100]. Proefferocytic effects were also observed for $\mathrm{AnxA1}_{2-50}$ and its cleavage-resistant form (CR- $A n x A 1_{2-50}$ ), which stimulated efferocytosis in vitro by human and mice bone-marrow derived macrophages [26]. This effect was confirmed in vivo in a zymosan-induced peritonitis model, when the peptides significantly reduced exudate neutrophil counts and increased the number of macrophages containing ingested PMN [26].

Once phagocytic removal of apoptotic cells has failed, neutrophils undergo secondary postapoptotic necrosis, probably leading to the leakage of cytotoxic and antigenic intracellular contents into the surrounding tissue [63]. Blume and col. (2012) revealed, in two complementary studies, the role of externalized AnxAl as a fail-safe mechanism after neutrophil transition from apoptosis to secondary necrosis. First, they described AnxA1 externalization during secondary necrosis, which in turn promotes the removal of dying cells and prevents proinflammatory cytokine production [66]. In the second study, they demonstrated that in vitro AnxA1 proteolysis during secondary necrosis generates a monocytic "find-me" signal, contributing to the recruitment of monocytes and consequently preventing inflammation [63].

The removal of apoptotic cells has dual importance: prevention of potentially toxic content release and induction 
of macrophage reprogramming toward a resolving phenotype [101-103], another key event to restore tissue homeostasis. Accordingly, AnxAl-induced efferocytosis is coupled with increased release of transforming growth factor- (TGF-) $\beta$ and lower levels of the proinflammatory cytokine IL-6 [65, 67]. In agreement with this observation, impaired phagocytosis in AnxA1-deficient macrophages is mirrored by increased release of tumor necrosis factor- (TNF-) $\alpha$ and IL- 6 [99]. Supporting an immunomodulatory effect of AnxA1 on cytokine production, AnxAl-null mice showed increased mortality in a model of LPS-induced endotoxic shock which was correlated with increased activation of inflammatory cells [104]. The authors detected delayed and more prolonged increase in the levels of TNF- $\alpha$, IL-1, and IL- 6 in the blood of AnxAl-null mice, as well as increased production of these cytokines by AnxA1 KO macrophages [104]. This data is consistent with the increased production of IL- 6 and TNF by stimulated AnxA1 KO peritoneal macrophages in comparison to WT cells [105]. Moreover, in vitro studies linked AnxA1 to brain homeostasis, demonstrating that exogenous AnxA1 can suppress microglial activation, limiting indiscriminate phagocytosis of healthy neurones and nitric oxide (NO) production during the phagocytic reaction [69]. Recently, the functional role of macrophage-derived AnxA1 in modulating hepatic inflammation and fibrogenesis during nonalcoholic steatohepatitis (NASH) progression was documented [68]. $\mathrm{NASH}$ in AnxA1 KO mice was characterized by enhanced lobular inflammation resulting from increased macrophage recruitment and exacerbation of the proinflammatory M1 phenotype [68]. In line with these results, AnxAl administration to liver macrophages suppressed M1 activation, characterized by reduced expression of iNOS and IL-12p40, and increased IL-10 expression. Interestingly, activation of FPR2 by AnxA1 skewed M1 macrophages to anti-inflammatory M2-like cells, attenuating the expression of IL-6, IL-1 $\beta$, and TNF- $\alpha$ [44]. Furthermore, Cooray and col. (2013) revealed an AnxA1-specific FPR2/ALX proresolving signal pathway centered in $\mathrm{p} 38$, leading to the production of IL-10 by human monocytes, an effect replicated in vivo after intraperitoneal AnxAl injection [47].

Although uptake of secondary necrotic leukocytes was shown to be AnxAl independent, the protein has an antiinflammatory action on macrophages, since phagocytosis of AnxA1 knock-down necrotic cells induced increased release of proinflammatory cytokines TNF, IL- 6 , and IL- $1 \beta$ by phagocytic cells [66]. Pupjalis and col. (2011) added knowledge to the immunosuppressive actions of AnxAl derived from apoptotic PMN. According to the authors, the treatment of human monocytes with AnxAl-containing supernatant of apoptotic granulocytes or Ac2-26 peptide results in a significantly diminished release of proinflammatory cytokines when the monocytes are subsequently challenged with endotoxin [70].

Taken together, these findings indicate that AnxAlinduced efferocytosis collaborates with the resolution of inflammation by promoting the elimination of effete neutrophils allied to an alternative macrophage activation that downregulates the production of proinflammatory mediators. Such events pave the way to the resolution of inflammation.

\section{Concluding Remarks}

AnxA1 is a GC-regulated protein that modulates a wide range of cellular and molecular steps of the inflammatory response and is deeply involved in the endogenous mechanisms that are activated to bring about proper resolution. So, it is reasonable to suppose that AnxAl-based pharmacologic strategies could be as effective as steroids, without their metabolic side effects. We have discussed here the ability of AnxA1 and its mimetic peptides to limit neutrophil accumulation in the tissue. Besides limiting neutrophil recruitment and increasing neutrophil apoptosis, AnxAl promotes apoptotic neutrophil clearance by modulating monocyte recruitment and enhancing efferocytosis. Indeed, AnxA1 contributes to tissue homeostasis by inducing macrophage reprogramming toward a resolving phenotype. The combination of these mechanisms results in an effective resolution of inflammation, pointing to AnxAl and its mimetic peptides as promising therapeutic agents for treating inflammatory diseases.

The promising findings on the potential therapeutic use of AnxAl in inflammatory diseases have stimulated the development of pharmaceutical formulations containing AnxA1 mimetic peptides, such as the controlled-release hydrogels for dermal wound repair application [106] and targeted polymeric nanoparticles [107]. The latter demonstrated ability to enhance resolution in zymosan-induced peritonitis [107], promote colonic wounds healing [42], and protect hypercholesterolemic mice against advanced atherosclerosis [108]. These pharmaceutical strategies offer further benefits, overcoming the critical pharmacokinetics of short peptides in vivo, protecting them from proteolysis during pharmacological treatment, and facilitating the delivery to injury sites.

\section{Abbreviations}

Ac2-26: $\quad$ Peptide from N-terminal portion of annexin $\mathrm{Al}$ (residues 2-26)

AnxA1: Annexin A1

FPR2/ALXR: Formyl peptide receptor 2/lipoxin A4 receptor

Boc-1: $\quad$ N-t-Boc-Met-Leu-Phe

Dexa: $\quad$ Dexamethasone

ERK1/2: $\quad$ Extracellular signal-regulated kinase

FPR: $\quad$ Formyl peptide receptor

GC: $\quad$ Glucocorticoid

ICAM-1: Intercellular adhesion molecule-1

i.pl: $\quad$ Intrapleural

IL: Interleukin

I $\kappa$ B- $\alpha$ : $\quad$ Inhibitory kappa B alpha

KO: $\quad$ Knockout

LPS: Lipopolysaccharide

Mcl-1: $\quad$ Myeloid cell leukemia-1

NF- $\kappa$ B: $\quad$ Nuclear factor kappa B

PMN: Polymorphonuclear

SAnxA1: $\quad$ SuperAnxA1 or cleavage-resistant AnxA1

TGF- $\beta$ : Transforming growth factor- $\beta$

TNF: $\quad$ Tumor necrosis factor 
VCAM-1: Vascular cell adhesion molecule-1

WT: Wild-type

zVAD-fmk: Benzyloxycarbonyl-Val-Ala-Asp-

fluoromethylketone.

\section{Conflict of Interests}

The authors declare that there is no conflict of interests regarding the publication of this paper.

\section{Acknowledgments}

The authors would like to acknowledge the funding from Conselho Nacional de Desenvolvimento Científico e Tecnológico ( $\mathrm{CNPq}$, Brazil), Comissão de Aperfeiçoamento de Pessoal do Ensino Superior (CAPES, Brazil), Fundação do Amparo a Pesquisa de Minas Gerais (FAPEMIG, Brazil), Instituto Nacional de Ciência e Tecnologia (INCT in Dengue), and the European Community's Seventh Framework Programme (FP7-2007-2013, Timer Consortium) under Grant Agreement HEALTH-F4-2011-281608. The authors apologize to their colleagues if their original contributions could not be included in the list of references due to space limitations.

\section{References}

[1] R. Medzhitov, "Inflammation 2010: new adventures of an old flame," Cell, vol. 140, no. 6, pp. 771-776, 2010.

[2] M. T. Silva and M. Correia-Neves, "Neutrophils and macrophages: the main partners of phagocyte cell systems," Frontiers in Immunology, vol. 3, article 174, 2012.

[3] J. M. Hallett, A. E. Leitch, N. A. Riley, R. Duffin, C. Haslett, and A. G. Rossi, "Novel pharmacological strategies for driving inflammatory cell apoptosis and enhancing the resolution of inflammation," Trends in Pharmacological Sciences, vol. 29, no. 5, pp. 250-257, 2008.

[4] S. E. Headland and L. V. Norling, "The resolution of inflammation: principles and challenges," Seminars in Immunology, vol. 27, no. 3, pp. 149-160, 2015.

[5] C. Nathan and A. Ding, "Nonresolving inflammation," Cell, vol. 140, no. 6, pp. 871-882, 2010.

[6] D. Gilroy and R. De Maeyer, "New insights into the resolution of inflammation," Seminars in Immunology, vol. 27, no. 3, pp. 161-168, 2015.

[7] C. N. Serhan and J. Savill, "Resolution of inflammation: the beginning programs the end," Nature Immunology, vol. 6, no. 12, pp. 1191-1197, 2005.

[8] L. P. Sousa, A. L. Alessandri, V. Pinho, and M. M. Teixeira, "Pharmacological strategies to resolve acute inflammation," Current Opinion in Pharmacology, vol. 13, no. 4, pp. 625-631, 2013.

[9] C. N. Serhan, S. Yacoubian, and R. Yang, "Anti-inflammatory and proresolving lipid mediators," Annual Review of Pathology: Mechanisms of Disease, vol. 3, pp. 279-312, 2008.

[10] C. N. Serhan, J. Dalli, R. A. Colas, J. W. Winkler, and N. Chiang, "Protectins and maresins: new pro-resolving families of mediators in acute inflammation and resolution bioactive metabolome," Biochimica et Biophysica Acta, vol. 1851, no. 4, pp. 397413, 2015.
[11] J. P. Vago, C. R. Nogueira, L. P. Tavares et al., "Annexin A1 modulates natural and glucocorticoid-induced resolution of inflammation by enhancing neutrophil apoptosis," Journal of Leukocyte Biology, vol. 92, no. 2, pp. 249-258, 2012.

[12] M. Perretti and J. Dalli, "Exploiting the Annexin A1 pathway for the development of novel anti-inflammatory therapeutics," British Journal of Pharmacology, vol. 158, no. 4, pp. 936-946, 2009.

[13] P. Raynal and H. B. Pollard, "Annexins: the problem of assessing the biological role for a gene family of multifunctional calciumand phospholipid-binding proteins," Biochimica et Biophysica Acta-Biomembranes, vol. 1197, no. 1, pp. 63-93, 1994.

[14] V. Gerke and S. E. Moss, "Annexins: from structure to function," Physiological Reviews, vol. 82, no. 2, pp. 331-371, 2002.

[15] V. Gerke, C. E. Creutz, and S. E. Moss, "Annexins: linking $\mathrm{Ca}^{2+}$ signalling to membrane dynamics," Nature Reviews Molecular Cell Biology, vol. 6, no. 6, pp. 449-461, 2005.

[16] R. J. Flower and G. J. Blackwell, "Anti-inflammatory steroids induce biosynthesis of a phospholipase $\mathrm{A}_{2}$ inhibitor which prevents prostaglandin generation," Nature, vol. 278, no. 5703, pp. 456-459, 1979.

[17] G. Cirino and R. J. Flower, "Human recombinant lipocortin 1 inhibits prostacyclin production by human umbilical artery in vitro," Prostaglandins, vol. 34, no. 1, pp. 59-62, 1987.

[18] G. Cirino, R. J. Flower, J. L. Browning, L. K. Sinclair, and R. B. Pepinsky, "Recombinant human lipocortin 1 inhibits thromboxane release from guinea-pig isolated perfused lung," Nature, vol. 328, no. 6127, pp. 270-272, 1987.

[19] F. D'Acquisto, M. Perretti, and R. J. Flower, "Annexin-A1: a pivotal regulator of the innate and adaptive immune systems," British Journal of Pharmacology, vol. 155, no. 2, pp. 152-169, 2008.

[20] M. Perretti and F. D’Acquisto, "Annexin A1 and glucocorticoids as effectors of the resolution of inflammation," Nature Reviews Immunology, vol. 9, no. 1, pp. 62-70, 2009.

[21] A. Rosengarth, V. Gerke, and H. Luecke, "X-ray structure of fulllength annexin 1 and implications for membrane aggregation," Journal of Molecular Biology, vol. 306, no. 3, pp. 489-498, 2001.

[22] N.-J. Hu, J. Bradshaw, H. Lauter, J. Buckingham, E. Solito, and A. Hofmann, "Membrane-induced folding and structure of membrane-bound annexin A1 N-terminal peptides: implications for annexin-induced membrane aggregation," Biophysical Journal, vol. 94, no. 5, pp. 1773-1781, 2008.

[23] S. M. Oliani, M. J. Paul-Clark, H. C. Christian, R. J. Flower, and M. Perretti, "Neutrophil interaction with inflamed postcapillary venule endothelium alters annexin 1 expression," American Journal of Pathology, vol. 158, no. 2, pp. 603-615, 2001.

[24] U. Rescher, V. Goebeler, A. Wilbers, and V. Gerke, "Proteolytic cleavage of annexin 1 by human leukocyte elastase," Biochimica et Biophysica Acta-Molecular Cell Research, vol. 1763, no. 11, pp. 1320-1324, 2006.

[25] L. Vong, F. D’Acquisto, M. Pederzoli-Ribeil et al., "Annexin 1 cleavage in activated neutrophils: a pivotal role for proteinase 3," The Journal of Biological Chemistry, vol. 282, no. 41, pp. 2999830004, 2007.

[26] J. Dalli, A. P. Consalvo, V. Ray et al., "Proresolving and tissueprotective actions of annexin A1-based cleavage-resistant peptides are mediated by formyl peptide receptor 2/lipoxin A4 receptor," Journal of Immunology, vol. 190, no. 12, pp. 6478-6487, 2013. 
[27] M. Pederzoli-Ribeil, F. Maione, D. Cooper et al., "Design and characterization of a cleavage-resistant Annexin Al mutant to control inflammation in the microvasculature," Blood, vol. 116, no. 20, pp. 4288-4296, 2010.

[28] S. F. Smith, T. D. Tetley, A. Guz, and R. J. Flower, "Detection of lipocortin 1 in human lung lavage fluid: lipocortin degradation as a possible proteolytic mechanism in the control of inflammatory mediators and inflammation," Environmental Health Perspectives, vol. 85, pp. 135-144, 1990.

[29] F. H. C. Tsao, K. C. Meyer, X. Chen, N. S. Rosenthal, and J. Hu, "Degradation of annexin I in bronchoalveolar lavage fluid from patients with cystic fibrosis," American Journal of Respiratory Cell and Molecular Biology, vol. 18, no. 1, pp. 120-128, 1998.

[30] F. H. C. Tsao, Z. Xiang, A. Abbasi, and K. C. Meyer, "Neutrophil necrosis and annexin 1 degradation associated with airway inflammation in lung transplant recipients with cystic fibrosis," BMC Pulmonary Medicine, vol. 12, article 44, 2012.

[31] M. Perretti, S. K. Wheller, R. J. Flower, S. Wahid, and C. Pitzalis, "Modulation of cellular annexin I in human leukocytes infiltrating DTH skin reactions," Journal of Leukocyte Biology, vol. 65, no. 5, pp. 583-589, 1999.

[32] S. L. Williams, I. R. Milne, C. J. Bagley et al., "A proinflammatory role for proteolytically cleaved annexin A1 in neutrophil transendothelial migration," Journal of Immunology, vol. 185, no. 5, pp. 3057-3063, 2010.

[33] R. Hannon, J. D. Croxtall, S. J. Getting et al., "Aberrant inflammation and resistance to glucocorticoids in annexin $1^{-/-}$ mouse," The FASEB Journal, vol. 17, no. 2, pp. 253-255, 2003.

[34] Y. H. Yang, E. F. Morand, S. J. Getting et al., "Modulation of inflammation and response to dexamethasone by Annexin 1 in antigen-induced arthritis," Arthritis \& Rheumatism, vol. 50, no. 3, pp. 976-984, 2004.

[35] A. S. Damazo, S. Yona, R. J. Flower, M. Perretti, and S. M. Oliani, "Spatial and temporal profiles for anti-inflammatory gene expression in leukocytes during a resolving model of peritonitis," The Journal of Immunology, vol. 176, no. 7, pp. 4410-4418, 2006.

[36] F. N. E. Gavins, E. L. Hughes, N. A. P. S. Buss, P. M. Holloway, S. J. Getting, and J. C. Buckingham, "Leukocyte recruitment in the brain in sepsis: involvement of the annexin 1-FPR2/ALX antiinflammatory system," FASEB Journal, vol. 26, no. 12, pp. 49774989, 2012.

[37] A. P. Girol, K. K. O. Mimura, C. C. Drewes et al., "Anti-inflammatory mechanisms of the annexin $\mathrm{Al}$ protein and its mimetic peptide Ac2-26 in models of ocular inflammation in vivo and in vitro," Journal of Immunology, vol. 190, no. 11, pp. 5689-5701, 2013.

[38] W. Kao, R. Gu, Y. Jia et al., "A formyl peptide receptor agonist suppresses inflammation and bone damage in arthritis," British Journal of Pharmacology, vol. 171, no. 17, pp. 4087-4096, 2014.

[39] A. D. Gimenes, T. R. Andrade, C. B. Mello et al., "Beneficial effect of annexin A1 in a model of experimental allergic conjunctivitis," Experimental Eye Research, vol. 134, pp. 24-32, 2015.

[40] M. Drechsler, R. de Jong, J. Rossaint et al., "Annexin A1 counteracts chemokine-induced arterial myeloid cell recruitment," Circulation Research, vol. 116, no. 5, pp. 827-835, 2015.

[41] D. G. Souza, C. T. Fagundes, F. A. Amaral et al., "The required role of endogenously produced lipoxin A4 and annexin-1 for the production of IL-10 and inflammatory hyporesponsiveness in mice," Journal of Immunology, vol. 179, no. 12, pp. 8533-8543, 2007.
[42] G. Leoni, P. Neumann, N. Kamaly et al., "Annexin A1-containing extracellular vesicles and polymeric nanoparticles promote epithelial wound repair," Journal of Clinical Investigation, vol. 125, no. 3, pp. 1215-1227, 2015.

[43] R. D. Ye, F. Boulay, M. W. Ji et al., "International union of basic and clinical pharmacology. LXXIII. Nomenclature for the formyl peptide receptor (FPR) family," Pharmacological Reviews, vol. 61, no. 2, pp. 119-161, 2009.

[44] Y. Li, L. Cai, H. Wang et al., "Pleiotropic regulation of macrophage polarization and tumorigenesis by formyl peptide receptor-2," Oncogene, vol. 30, no. 36, pp. 3887-3899, 2011.

[45] S. Bena, V. Brancaleone, J. M. Wang, M. Perretti, and R. J. Flower, "Annexin A1 interaction with the FPR2/ALX receptor: identification of distinct domains and downstream associated signaling," The Journal of Biological Chemistry, vol. 287, no. 29, pp. 24690-24697, 2012.

[46] N. Chiang, I. M. Fierro, K. Gronert, and C. N. Serhan, "Activation of lipoxin A4 receptors by aspirin-triggered lipoxins and select peptides evokes ligand-specific responses in inflammation," The Journal of Experimental Medicine, vol. 191, no. 7, pp. 1197-1207, 2000.

[47] S. N. Cooray, T. Gobbetti, T. Montero-Melendez et al., "Ligandspecific conformational change of the G-protein-coupled receptor ALX/FPR2 determines proresolving functional responses," Proceedings of the National Academy of Sciences of the United States of America, vol. 110, no. 45, pp. 18232-18237, 2013.

[48] A. Walther, K. Riehemann, and V. Gerke, "A novel ligand of the formyl peptide receptor: annexin I regulates neutrophil extravasation by interacting with FPR," Molecular Cell, vol. 5, no. 5, pp. 831-840, 2000.

[49] J. Dalli, T. Montero-Melendez, S. McArthur, and M. Perretti, "Annexin A1 N-terminal derived peptide Ac2-26 exerts chemokinetic effects on human neutrophils," Frontiers in Pharmacology, vol. 3, article 28, 2012.

[50] V. Brancaleone, J. Dalli, S. Bena, R. J. Flower, G. Cirino, and M. Perretti, "Evidence for an anti-inflammatory loop centered on polymorphonuclear leukocyte formyl peptide receptor 2/lipoxin $\mathrm{A}_{4}$ receptor and operative in the inflamed microvasculature," The Journal of Immunology, vol. 186, no. 8, pp. 49054914, 2011.

[51] B. D. Levy, C. B. Clish, B. Schmidt, K. Gronert, and C. N. Serhan, "Lipid mediator class switching during acute inflammation: signals in resolution," Nature Immunology, vol. 2, no. 7, pp. 612$619,2001$.

[52] O. Haworth, M. Cernadas, R. Yang, C. N. Serhan, and B. D. Levy, "Resolvin E1 regulates interleukin 23, interferon- $\gamma$ and lipoxin A4 to promote the resolution of allergic airway inflammation," Nature Immunology, vol. 9, no. 8, pp. 873-879, 2008.

[53] C. Nathan, "Neutrophils and immunity: challenges and opportunities," Nature Reviews Immunology, vol. 6, no. 3, pp. 173-182, 2006.

[54] R. P. G. Hayhoe, A. M. Kamal, E. Solito, R. J. Flower, D. Cooper, and M. Perretti, "Annexin 1 and its bioactive peptide inhibit neutrophil-endothelium interactions under flow: indication of distinct receptor involvement," Blood, vol. 107, no. 5, pp. 21232130, 2006

[55] D. H. Kusters, M. L. Chatrou, B. A. Willems et al., "Pharmacological treatment with annexin A1 reduces atherosclerotic plaque burden in LDLR-/- mice on western type diet," PLoS ONE, vol. 10, no. 6, Article ID e0130484, 2015.

[56] L. H. K. Lim, E. Solito, F. Russo-Marie, R. J. Flower, and M. Perretti, "Promoting detachment of neutrophils adherent to 
murine postcapillary venules to control inflammation: effect of lipocortin 1," Proceedings of the National Academy of Sciences of the United States of America, vol. 95, no. 24, pp. 14535-14539, 1998.

[57] E. Solito, A. Kamal, F. Russo-Marie, J. C. Buckingham, S. Marullo, and M. Perretti, "A novel calcium-dependent proapoptotic effect of annexin 1 on human neutrophils," The FASEB Journal, vol. 17, no. 11, pp. 1544-1546, 2003.

[58] H. J. Strausbaugh and S. D. Rosen, "A potential role for annexin 1 as a physiologic mediator of glucocorticoid-induced L-selectin shedding from myeloid cells," The Journal of Immunology, vol. 166, no. 10, pp. 6294-6300, 2001.

[59] M. Perretti and R. J. Flower, "Modulation of IL-1-induced neutrophil migration by dexamethasone and lipocortin 1," The Journal of Immunology, vol. 150, no. 3, pp. 992-999, 1993.

[60] C. Zouki, S. Ouellet, and J. G. Filep, "The anti-inflammatory peptides, antiflammins, regulate the expression of adhesion molecules on human leukocytes and prevent neutrophil adhesion to endothelial cells," The FASEB Journal, vol. 14, no. 3, pp. 572-580, 2000.

[61] J. J. Moreno, "Antiflammin-2 prevents HL-60 adhesion to endothelial cells and prostanoid production induced by lipopolysaccharides," Journal of Pharmacology and Experimental Therapeutics, vol. 296, no. 3, pp. 884-889, 2001.

[62] R. A. P. Teixeira, K. K. O. Mimura, L. P. Araujo, K. V. Greco, and S. M. Oliani, "The essential role of annexin A1 mimetic peptide in the skin allograft survival," Journal of Tissue Engineering and Regenerative Medicine, 2013.

[63] K. E. Blume, S. Soeroes, H. Keppeler et al., "Cleavage of annexin A1 by ADAM10 during secondary necrosis generates a monocytic 'find-me' signal,' Journal of Immunology, vol. 188, no. 1, pp. 135-145, 2012.

[64] S. McArthur, T. Gobbetti, D. H. Kusters, C. P. Reutelingsperger, R. J. Flower, and M. Perretti, "Definition of a novel pathway centered on lysophosphatidic acid to recruit monocytes during the resolution phase of tissue inflammation," The Journal of Immunology, vol. 195, no. 3, pp. 1139-1151, 2015.

[65] M. Scannell, M. B. Flanagan, A. DeStefani et al., "Annexin-1 and peptide derivatives are released by apoptotic cells and stimulate phagocytosis of apoptotic neutrophils by macrophages," The Journal of Immunology, vol. 178, no. 7, pp. 4595-4605, 2007.

[66] K. E. Blume, S. Soeroes, M. Waibel et al., "Cell surface externalization of annexin A1 as a failsafe mechanism preventing inflammatory responses during secondary necrosis," The Journal of Immunology, vol. 183, no. 12, pp. 8138-8147, 2009.

[67] P. Maderna, S. Yona, M. Perretti, and C. Godson, "Modulation of phagocytosis of apoptotic neutrophils by supernatant from dexamethasone-treated macrophages and annexin-derived peptide $\mathrm{Ac}_{2-26}$ " The Journal of Immunology, vol. 174, no. 6, pp. 3727-3733, 2005.

[68] I. Locatelli, S. Sutti, A. Jindal et al., "Endogenous annexin A1 is a novel protective determinant in nonalcoholic steatohepatitis in mice," Hepatology, vol. 60, no. 2, pp. 531-544, 2014.

[69] S. McArthur, E. Cristante, M. Paterno et al., "Annexin A1: a central player in the anti-inflammatory and neuroprotective role of microglia," Journal of Immunology, vol. 185, no. 10, pp. 63176328, 2010.

[70] D. Pupjalis, J. Goetsch, D. J. Kottas, V. Gerke, and U. Rescher, "Annexin Al released from apoptotic cells acts through formyl peptide receptors to dampen inflammatory monocyte activation via JAK/STAT/SOCS signalling," EMBO Molecular Medicine, vol. 3, no. 2, pp. 102-114, 2011.
[71] P. Subramanian, I. Mitroulis, G. Hajishengallis, and T. Chavakis, "Regulation of tissue infiltration by neutrophils: role of integrin $\alpha 3 \beta 1$ and other factors," Current Opinion in Hematology, vol. 23, no. 1, pp. 36-43, 2016.

[72] M. Perretti, J. D. Croxtall, S. K. Wheller, N. J. Goulding, R. Hannon, and R. J. Flower, "Mobilizing lipocortin 1 in adherent human leukocytes downregulates their transmigration," Nature Medicine, vol. 2, no. 11, pp. 1259-1262, 1996.

[73] C. D. Gil, M. La, M. Perretti, and S. M. Oliani, "Interaction of human neutrophils with endothelial cells regulates the expression of endogenous proteins annexin 1, galectin-1 and galectin3," Cell Biology International, vol. 30, no. 4, pp. 338-344, 2006.

[74] T. S. Gastardelo, A. S. Damazo, J. Dalli, R. J. Flower, M. Perretti, and S. M. Oliani, "Functional and ultrastructural analysis of annexin $\mathrm{Al}$ and its receptor in extravasating neutrophils during acute inflammation," The American Journal of Pathology, vol. 174, no. 1, pp. 177-183, 2009.

[75] J. Dalli, L. V. Norling, D. Renshaw, D. Cooper, K.-Y. Leung, and M. Perretti, "Annexin 1 mediates the rapid anti-inflammatory effects of neutrophil-derived microparticles," Blood, vol. 112, no. 6, pp. 2512-2519, 2008.

[76] A. Montresor, L. Toffali, G. Constantin, and C. Laudanna, "Chemokines and the signaling modules regulating integrin affinity," Frontiers in Immunology, vol. 3, article 127, 2012.

[77] J. L. Bos, K. de Bruyn, J. Enserink et al., "The role of Rap1 in integrin-mediated cell adhesion," Biochemical Society Transactions, vol. 31, no. 1, pp. 83-86, 2003.

[78] B. Stuqui, M. de Paula-Silva, C. P. Carlos et al., "Ac2-26 mimetic peptide of annexin A1 inhibits local and systemic inflammatory processes induced by Bothrops moojeni venom and the Lys-49 phospholipase $\mathrm{A}_{2}$ in a rat model," PLoS ONE, vol. 10, no. 7, Article ID e0130803, 2015.

[79] B. C. Guido, M. Zanatelli, W. Tavares-De-Lima, S. M. Oliani, and A. S. Damazo, "Annexin-A1 peptide down-regulates the leukocyte recruitment and up-regulates interleukin-10 release into lung after intestinal ischemia-reperfusion in mice," Journal of Inflammation, vol. 10, no. 1, article 10, 2013.

[80] L. Miele, E. Cordella-Miele, A. Facchiano, and A. B. Mukherjee, "Novel anti-inflammatory peptides from the region of highest similarity between uteroglobin and lipocortin I," Nature, vol. 335, no. 6192, pp. 726-730, 1988.

[81] A. M. Kamal, R. P. G. Hayhoe, A. Paramasivam et al., "Antiflammin-2 activates the human formyl-peptide receptor like 1 ," TheScientificWorldJOURNAL, vol. 6, pp. 1375-1384, 2006.

[82] N. Chiang, C. N. Serhan, S.-E. Dahlén et al., "The lipoxin receptor ALX: potent ligand-specific and stereoselective actions in vivo," Pharmacological Reviews, vol. 58, no. 3, pp. 463-487, 2006.

[83] C. Summers, S. M. Rankin, A. M. Condliffe, N. Singh, A. M. Peters, and E. R. Chilvers, "Neutrophil kinetics in health and disease," Trends in Immunology, vol. 31, no. 8, pp. 318-324, 2010.

[84] T. Tak, K. Tesselaar, J. Pillay, J. A. M. Borghans, and L. Koenderman, "What's your age again? Determination of human neutrophil half-lives revisited," Journal of Leukocyte Biology, vol. 94, no. 4, pp. 595-601, 2013.

[85] J. G. Filep and D. El Kebir, "Neutrophil apoptosis: a target for enhancing the resolution of inflammation," Journal of Cellular Biochemistry, vol. 108, no. 5, pp. 1039-1046, 2009.

[86] D. El Kebir, L. József, and J. G. Filep, “Opposing regulation of neutrophil apoptosis through the formyl peptide receptor-like 1/lipoxin $\mathrm{A}_{4}$ receptor: implications for resolution of inflammation," Journal of Leukocyte Biology, vol. 84, no. 3, pp. 600-606, 2008 . 
[87] Y. Tabe, L. Jin, R. Contractor et al., "Novel role of HDAC inhibitors in AML1/ETO AML cells: activation of apoptosis and phagocytosis through induction of annexin A1," Cell Death and Differentiation, vol. 14, no. 8, pp. 1443-1456, 2007.

[88] T. Montero-Melendez, J. Dalli, and M. Perretti, "Gene expression signature-based approach identifies a pro-resolving mechanism of action for histone deacetylase inhibitors," Cell Death and Differentiation, vol. 20, no. 4, pp. 567-575, 2013.

[89] A. G. Rossi, D. A. Sawatzky, A. Walker et al., "Cyclin-dependent kinase inhibitors enhance the resolution of inflammation by promoting inflammatory cell apoptosis," Nature Medicine, vol. 12, no. 9, pp. 1056-1064, 2006.

[90] E. E. McGrath, H. M. Marriott, A. Lawrie et al., “TNF-related apoptosis-inducing ligand (TRAIL) regulates inflammatory neutrophil apoptosis and enhances resolution of inflammation," Journal of Leukocyte Biology, vol. 90, no. 5, pp. 855-865, 2011.

[91] C. D. Lucas, D. A. Dorward, M. A. Tait et al., "Downregulation of Mcl-1 has anti-inflammatory pro-resolution effects and enhances bacterial clearance from the lung," Mucosal Immunology, vol. 7, no. 4, pp. 857-868, 2014.

[92] I. K. H. Poon, C. D. Lucas, A. G. Rossi, and K. S. Ravichandran, "Apoptotic cell clearance: basic biology and therapeutic potential," Nature Reviews Immunology, vol. 14, no. 3, pp. 166180, 2014.

[93] P. Maderna and C. Godson, "Phagocytosis of apoptotic cells and the resolution of inflammation," Biochimica et Biophysica Acta (BBA)-Molecular Basis of Disease, vol. 1639, no. 3, pp. 141-151, 2003.

[94] O. Soehnlein, L. Lindbom, and C. Weber, "Mechanisms underlying neutrophil-mediated monocyte recruitment," Blood, vol. 114, no. 21, pp. 4613-4623, 2009.

[95] H. L. Wright, R. J. Moots, R. C. Bucknall, and S. W. Edwards, "Neutrophil function in inflammation and inflammatory diseases," Rheumatology, vol. 49, no. 9, pp. 1618-1631, 2010.

[96] K. S. Ravichandran, "Beginnings of a good apoptotic meal: the find-me and eat-me signaling pathways," Immunity, vol. 35, no. 4, pp. 445-455, 2011.

[97] S. Arur, U. E. Uche, K. Rezaul et al., "Annexin I is an endogenous ligand that mediates apoptotic cell engulfment," Developmental Cell, vol. 4, no. 4, pp. 587-598, 2003.

[98] P. Maderna, D. C. Cottell, T. Toivonen et al., "FPR2/ALX receptor expression and internalization are critical for lipoxin A4 and annexin-derived peptide-stimulated phagocytosis," The FASEB Journal, vol. 24, no. 11, pp. 4240-4249, 2010.

[99] S. Yona, S. E. M. Heinsbroek, L. Peiser, S. Gordon, M. Perretti, and R. J. Flower, "Impaired phagocytic mechanism in annexin 1 null macrophages," British Journal of Pharmacology, vol. 148, no. 4, pp. 469-477, 2006.

[100] J. Dalli, C. P. Jones, D. M. Cavalcanti, S. H. Farsky, M. Perretti, and S. M. Rankin, "Annexin A1 regulates neutrophil clearance by macrophages in the mouse bone marrow," The FASEB Journal, vol. 26, no. 1, pp. 387-396, 2012.

[101] R. E. Voll, M. Herrmann, E. A. Roth, C. Stach, J. R. Kalden, and I. Girkontaite, "Immunosuppressive effects of apoptotic cells," Nature, vol. 390, no. 6658, pp. 350-351, 1997.

[102] V. A. Fadok, D. L. Bratton, A. Konowal, P. W. Freed, J. Y. Westcott, and P. M. Henson, "Macrophages that have ingested apoptotic cells in vitro inhibit proinflammatory cytokine production through autocrine/paracrine mechanisms involving TGF- $\beta$, PGE2, and PAF," The Journal of Clinical Investigation, vol. 101, no. 4, pp. 890-898, 1998.
[103] M.-L. N. Huynh, V. A. Fadok, and P. M. Henson, "Phosphatidylserine-dependent ingestion of apoptotic cells promotes TGF- $\beta 1$ secretion and the resolution of inflammation," Journal of Clinical Investigation, vol. 109, no. 1, pp. 41-50, 2002.

[104] A. S. Damazo, S. Yona, F. D’Acquisto, R. J. Flower, S. M. Oliani, and M. Perretti, "Critical protective role for annexin 1 gene expression in the endotoxemic murine microcirculation," American Journal of Pathology, vol. 166, no. 6, pp. 1607-1617, 2005.

[105] Y. H. Yang, D. Aeberli, A. Dacumos, J. R. Xue, and E. F. Morand, "Annexin-1 regulates macrophage IL-6 and TNF via glucocorticoid-induced leucine zipper," Journal of Immunology, vol. 183, no. 2, pp. 1435-1445, 2009.

[106] P. Del Gaudio, F. De Cicco, R. P. Aquino et al., "Evaluation of in situ injectable hydrogels as controlled release device for ANXA1 derived peptide in wound healing," Carbohydrate Polymers, vol. 115, pp. 629-633, 2015.

[107] N. Kamaly, G. Fredman, M. Subramanian et al., "Development and in vivo efficacy of targeted polymeric inflammation-resolving nanoparticles," Proceedings of the National Academy of Sciences of the United States of America, vol. 110, no. 16, pp. 65066511, 2013.

[108] G. Fredman, N. Kamaly, S. Spolitu et al., “Targeted nanoparticles containing the proresolving peptide Ac2-26 protect against advanced atherosclerosis in hypercholesterolemic mice," Science Translational Medicine, vol. 7, no. 275, Article ID 275ra20, 2015. 


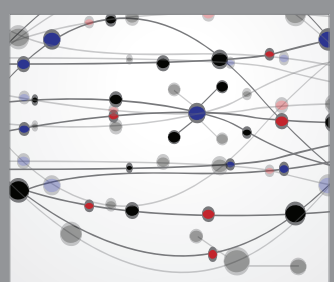

The Scientific World Journal
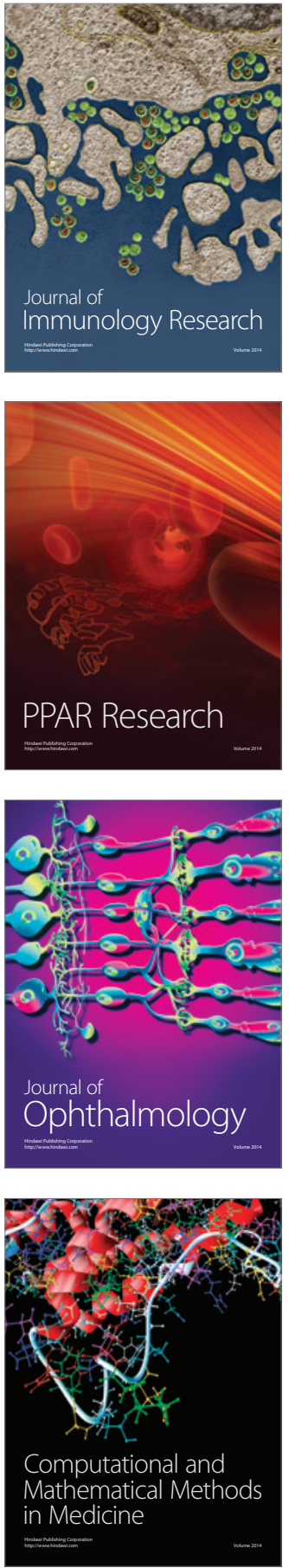

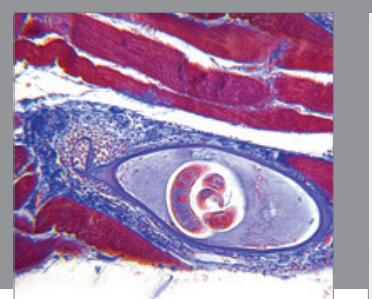

Gastroenterology Research and Practice

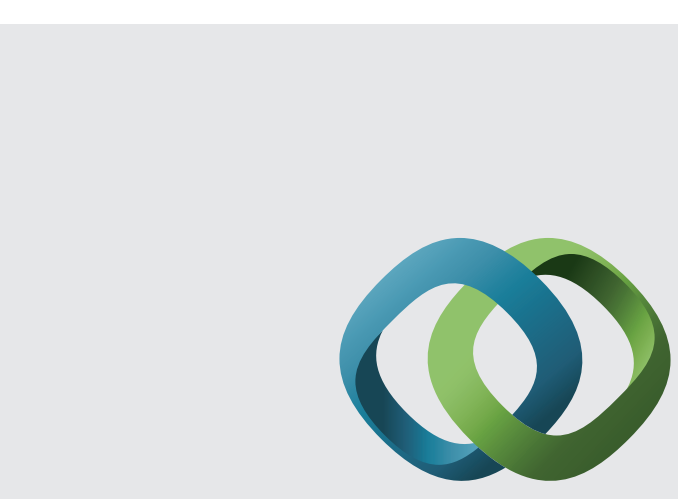

\section{Hindawi}

Submit your manuscripts at

http://www.hindawi.com
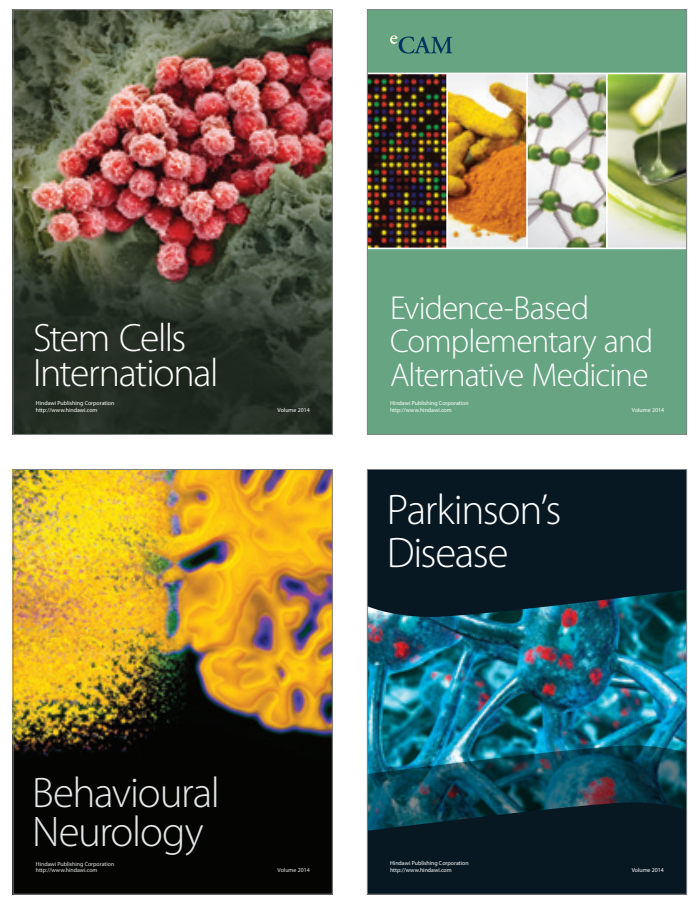
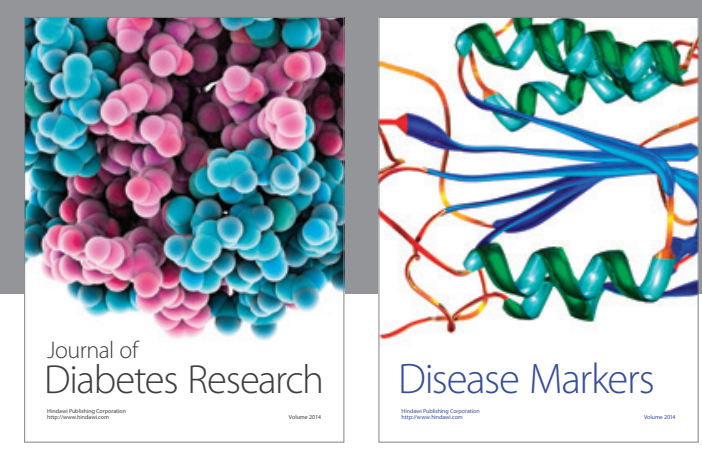

Disease Markers
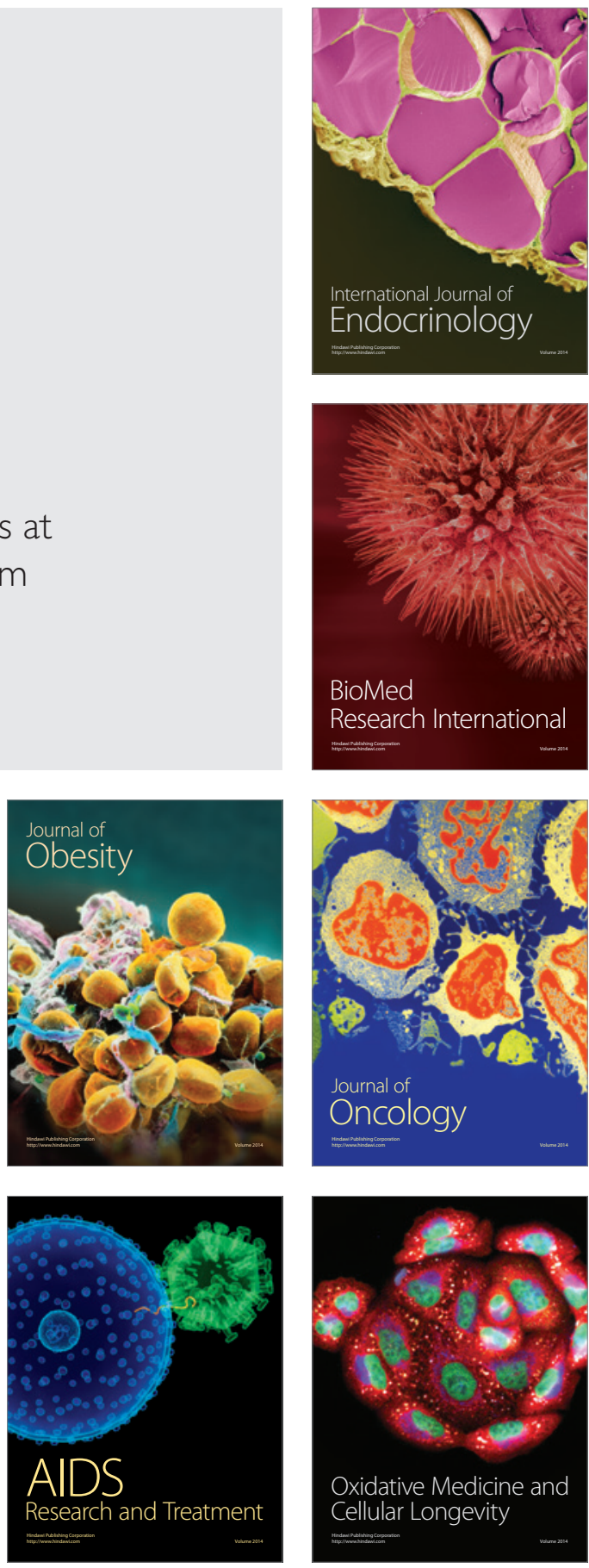